\title{
Tuberculosis extrapulmonar en embarazada. Primer caso en el Área de Salud de Pavas
}

\author{
(Extra pulmonary tuberculosis in a pregnant woman. First case seeing at the \\ Pavas Health Area)
}

\author{
Adriana González- Vizcaíno,Alcira Ramírez -Salas
}

\begin{abstract}
Resumen:
La tuberculosis es la segunda causa de muerte por enfermedades infecciosas en el mundo, precedida solo por el Virus de Inmunodeficiencia Humana y Síndrome de Inmunodeficiencia Adquirida (sida), y es la primera causa de muerte por enfermedades infecciosas en las mujeres. La presentación de la tuberculosis en la mujer embarazada es similar a la de la no embarazada, pero el diagnóstico puede retardarse por la naturaleza no específica de los primeros síntomas y la frecuencia de malestar y fatiga en el embarazo. Este es el primer caso de tuberculosis en una embarazada documentado en el Área de Salud de Pavas.
\end{abstract}

Descriptores: Tuberculosis extra-pulmonar, embarazo, Pavas

\begin{abstract}
:
Tuberculosis is the world's second commonest cause of death from infectious disease, after HIV/AIDS and is the first infectious cause of death among women. The clinical presentation of tuberculosis does not differ in pregnant and not pregnant women, but the diagnosis can be delayed because of increased rates of malaise and fatigue in noninfected pregnant women. This is the first case of pregnant woman with extra pulmonary tuberculosis documen-ted in the Area of Health of Pavas.
\end{abstract}

Key Words: Extrapulmonary tuberculosis, pregnant, Pavas

Recibido: 26 de noviembre de 2008

Aceptado: 17 de febrero de 2009

La tuberculosis $(\mathrm{Tb})$ es la segunda causa de muerte por enfermedades infecciosas en el mundo, precedida solo por el Virus de Inmunodeficiencia Humana y el Síndrome de Inmunodeficiencia Adquirida (sida). ${ }^{1}$

$\mathrm{La} \mathrm{Tb}$ en el embarazo ha sido un tema de interés y controversia desde los días de Hipócrates, quien consideraba que el embarazo tenía un efecto beneficioso sobre la

Clínica de Pavas-COOPESALUD R.L.

Abreviaturas: $\mathrm{Tb}$, tuberculosis

Correspondencia: Adriana González Vizcaíno. Apartado postal 8461200, Pavas, Costa Rica. Email: agonzalez@coopesalud.com

ISSN 0001-6002/2009/51/2/119-120

Acta Médica Costarricense, (O2009

Colegio de Médicos y Cirujanos tuberculosis, ${ }^{2}$ concepto que se mantuvo hasta el siglo XIX, a mediados del cual aparecieron opiniones diametralmente opuestas y comunicados médicos que señalaban el efecto negativo del embarazo sobre la $\mathrm{Tb}$. Estudios más recientes demuestran que no existen diferencias en la incidencia de $\mathrm{Tb}$ entre embarazadas y no embarazadas, ${ }^{3}$ pero el diagnóstico puede retardarse por la naturaleza no específica de los primeros síntomas y la frecuencia de malestar y fatiga en el embarazo. ${ }^{4}$

El sitio de localización más común es pulmonar; el porcentaje con localización extrapulmonar varía y, según los distintos reportes, oscila entre el $5 \%{ }^{4}$ y el $53 \% .^{5}$ El diagnóstico no es tan fácil como en la Tb pulmonar y además la biopsia o intervención quirúrgica durante el embarazo no es posible por el riesgo de parto de pretérmino, pobre acceso a las lesiones y riesgo anestésico para el feto. ${ }^{6}$

El tratamiento debe iniciarse tan pronto el diagnóstico es confirmado. Los 4 medicamentos de primera línea para el tratamiento de la $\mathrm{Tb}$ : isoniacida, rifampicina, etambutol y pirazinamida, no son teratogénicos, por lo tanto, se pueden utilizar con seguridad durante el embarazo ${ }^{1,6,7}$ y durante la lactancia materna. ${ }^{1,4}$

Los efectos de la Tb extrapulmonar sobre el embarazo varían según el sitio de localización de esta, la severidad y la duración de la enfermedad. ${ }^{6}$ Es importante resaltar que los resultados en aquellas embarazadas en quienes se diagnosticó la enfermedad tempranamente, son similares a los de aquellas que no la tuvieron. ${ }^{8}$

\section{Presentación del caso}

Paciente de 27 años de edad, nicaragüense, residente en Costa Rica desde 1999, en la comunidad urbano marginal de Oscar Felipe, Pavas-San José. Conocida sana. Sin antecedentes familiares o personales de tuberculosis.

Primigesta con control prenatal temprano. A las 25 semanas consultó al Servicio de Urgencias de la Clínica de Pavas por dorsalgia. Tres días después lo hizo al Servicio de Emergencias de un hospital nacional, por cuadro febril, escalofríos y tos con flemas, dolor ocular y dolor abdominal. El examen físico se registró como normal y se ingresó para estudios. Tacto vaginal: $1-2 \mathrm{~cm}$ de dilatación y un $40 \%$ borrado. Ultrasonido obstétrico normal: al segundo día de ingreso se describe: campos pulmonares con disminución de murmullo vesicular, en el izquierdo se auscultaron crépitos. 
Radiografía de tórax: consolidación basal izquierda con abolición de ángulo cardiofrénico y costodiafragmático. Se realizó toracentesis y el líquido era un exudado linfocitario, cuyo cultivo fue negativo.

A los 12 días de hospitalizada se le realizó cerclaje cervical y varios exámenes de laboratorio cuyos resultados estuvieron dentro de parámetros normales, así como VDRL y serología por VIH, ambas negativas.

La bacteriología del líquido pleural Tinción de auramina no demostró bacilos alcohol ácido resistentes. La tinción de Ziehl-Neelsen no demostró bacilos alcohol ácido resistentes.

El diagnóstico final fue: síndrome de derrame pleural izquierdo, que corresponde a un exudado inflamatorio con adenosina desaminasa elevada; y se inició tratamiento antifímico. La paciente fue también valorada por el Servicio de Trabajo Social, y al cabo de 16 días de internamiento fue egresada con mejor estado general y los diagnósticos: pleuresía tuberculosa, embarazo de 28 semanas e incompetencia ístmico cervical, y los siguientes medicamentos: Rifampicina $600 \mathrm{mg} / \mathrm{d}$, Isoniacida $300 \mathrm{mg} / \mathrm{d}$, Pirazinamida $1500 \mathrm{mg} / \mathrm{d}$, Etambutol $1200 \mathrm{mg} / \mathrm{d}$ y Piridoxina $25 \mathrm{mg} / \mathrm{d}$.

El parto fue a las 31.2/7 semanas, el producto fue una niña viva (1665 gramos de peso y APGAR 4-6), quien fue internada en el Servicio de Neonatología del Hospital de Niños durante 37 días; diagnósticos: recién nacido de pretérmino adecuado para la edad gestacional, síndrome de insuficiencia respiratoria, sepsis neonatal temprana e ictericia multifactorial y contacto con TB. Ultrasonidos de cerebro, abdomen y riñones fueron normales, el líquido cefalorraquídeo y 3 jugos gástricos fueron negativos por BK; se le prescribió Isoniacida por 3 meses y vitaminas A y B6. La niña evolucionó satisfactoriamente. Recibió lactancia materna y leche de soya con buena ganancia ponderal y su crecimiento y desarrollo han sido adecuados.

\section{Discusión y conclusiones}

El Área de Salud de Pavas es considerada una de las áreas de riesgo para $\mathrm{Tb}$; la incidencia anual en los últimos 5 años es de 17-19 casos/100 000 habitantes. Este es el primer caso de tuberculosis en una embarazada documentado en esta Área.

A la paciente se le diagnóstico $\mathrm{Tb}$ pleural cuando cursaba el tercer trimestre de embarazo, al cabo de 13 días del inicio de síntomas, lo que parece poco tiempo si se le compara con un estudio realizado en un área de Londres con alta prevalencia de tuberculosis, donde el promedio de días que transcurrieron para realizar el diagnóstico, en la presentación extrapulmonar, fue de 180, mencionando como razones la presentación tardía (52\%), lo poco específicos de los síntomas (38\%) y el pobre cumplimiento y seguimiento a la paciente. ${ }^{5}$

En nuestra paciente se llegó al diagnóstico con ayuda de métodos convencionales -clínica y radiología- y no convencionales -actividad de la adenosina desaminasa-, técnica que surgió en 1980 y ha demostrado ser de gran rendimiento, fácil ejecución, rápida y de bajo costo, y ha confirmado su gran utilidad para el diagnóstico de la $\mathrm{Tb}$ pleural, ${ }^{9}$ mientras se espera el resultado del cultivo, lo cual tiene un impacto favorable en el paciente. ${ }^{10}$

El parto fue vía vaginal de pretérmino, muy probablemente favorecido por la incontinencia istmico cervical, más que por la $\mathrm{Tb}$.

Tal y como se actuó con la hija de esta paciente y de acuerdo con la bibliografía consultada, la Tb congénita fue descartaday, posteriormente, se proporcionóquimioprofilaxis por 3 meses adicionando piridoxina, por cuanto la leche materna contiene niveles bajos de esa vitamina y la isoniacida causa su deficiencia. ${ }^{2}$

La paciente mantuvo adherencia al tratamiento y un seguimiento mensual a local y hospitalario. Pese a que el diagnóstico se realizó en una etapa avanzada del embarazo, tanto la paciente como su hija fueron abordadas con éxito por diferentes funcionarios de los servicios de salud: neumólogo, médico general, ginecoobstetra, pediatra, neonatólogo, trabajadora social, enfermera, auxiliar de enfermería y asistente técnico de atención primaria, como recomienda la bibliografía consultada.

La presentación de la $\mathrm{Tb}$ en la embarazada debe sospecharse ante la presencia de síntomas, historia familiar de $\mathrm{Tb}$, historia personal de $\mathrm{Tb}$ en el pasado, posibilidad de infección por VIH, TB en el área de residencia (o laboral o estudiantil). ${ }^{1}$ El diagnóstico y tratamiento tempranos durante la gestación reversan el impacto negativo en los resultados perinatales.

\section{Referencias}

1. Frieden T, Sterling T, Munsiff S, Watt C, Dye C. Tuberculosis. Lancet 2003; 362: 887-9.

2. Tripathy S and Tripathy S. Tuberculosis and pregnancy. Int J Gynaecol Obstet 2003;80:247-253.

3. Ormerod P. Tuberculosis in pregnancy and the puerperium. Thorax 2001; 56:494-499.

4. Llewellyn M, Cropley I, Wilkinson R, Davidson R. Tuberculosis diagnosed during pregnancy: a prospective study from London. Thorax 2000; 55:129-132.

5. Kothari A, Mahadevan N, Girling J. Tuberculosis and pregnancyResults of a study in al high prevalence area in London. Eur J Obstet Gynecol Reprod Biol 2002; 126:88-55.

6. Jana N, Vasishta K, Subhas C, Kushagradhi G. Obstetrical outcomes among women with extrapulmonary tuberculosis. NEJM. 1999; 341:645-649

7. Committee on drugs. American Academy of Pediatrics. The transfer of drug and other chemicals into human milk. Pediatrics 2001;108 :776789.

8. Baba K, Hoosen A, Langeland N, Dyrhol A. Adenosine Deaminase Activity is a sensitive marker for the diagnosis of tuberculosis pleuritis in patients with very low CD 4 counts. PLoS ONE. 2008;3:1-5. Disponible en En: www.plosone.org. Consultado el 14 de setiembre 2008.

9. Coitinho C, San Martin R, Mier C, Rodríguez R, Zunino S, Rivas C. Utilidad de la dosificación de adenosin deaminasa en el diagnóstico de la tuberculosis pleural. Primera experiencia nacional. Rev Med Urug 2007; 23:19-24.

10. Bandyopadhyay D, Gupta S, Banerjee S, Gupta S, Ray D, Bhattacharya S, Bhattacharya B. Adenosine deaminase estimation and multiplex polymerase chain reaction in diagnosis of extra-pulmonary tuberculosis. Int J Tuberc Lung Dis. 2008; 10:1203-1208. 